\title{
ОНЛАЙН КОГНІТИВНО-ПОВЕДІНКОВА ТЕРАПІЯ ЕМОЦІЙНОГО ДИСТРЕСУ СТУДЕНТІВ У ПЕРІОД ПАНДЕМІї COVID-19
}

\author{
Засскіна Лариса \\ Волинський національний університет імені Лесі Українки \\ м. Луцьк, Україна \\ zasyekina.larisa@vnu.edu.ua \\ ORCHID ID: https://orcid.org/0000-0001-8456-0774
}

Мета. COVID-19 пандемія на сучасному етапі трансформується у другу хвилю пандемії, пов'язану 3 пандемією розладів психічного здоров'я. Незважаючи на той факт, що студенти упродовж тривалого часу не вважалися вразливою категорією населення у період пандемії, результати останніх досліджень доводять, що вони переживають актуальний стрес, тривожність, самотність та депресію в умовах вимушеної соціальної ізоляції. Мета дослідження полягає в емпіричному вивченні емоційного дистресу студентів під час пандемії COVID-19, та науковому обгрунтуванні авторського онлайн ресурсу, базованому на когнітивно-поведінковій терапії (КПТ).

Методи. У дослідженні використовувалися методи теоретичного та емпіричного дослідження, зокрема психодіагностичний інструментарій, представлений шкалою психологічного благополуччя К. Ріфф, шкалою депресії А. Бека, шкалою резілієнтності С. Хамса та ін., шкалою тривоги А. Бека. Для тематичного аналізу творів студентів використовувалася комп'ютерна програма Linguistic Inquiry and Word Count (LIWC).

Результати дослідження психологічного благополуччя свідчать про те, що найнижчий рівень вираження мають субшкали позитивного ставлення до інших, самоприйняття, цілі в житті та управління оточенням. Тому при розробці онлайн ресурсу саме ці аспекти психологічного благополуччя були враховані. Результати лінійного регресійного аналізу свідчать про те, що тривожність, депресія та резілієнтність сукупно $є$ значущим предиктором психологічного благополуччя. Водночас лише депресія $\epsilon$ незалежним значущим предиктором психологічного благополуччя студентів. Враховуючи тривожність та самотність як основні проблеми, про які зазначали студенти у своїх творах, а також соціальну тривожність, яка зростає в умовах неможливості вдосконалювати комунікативні вміння під час пандемії, ресурс був спрямований на зменшення цих негативних емоційні станів. Відповідно до трьох блоків онлайн ресурс отримав назву 3 (ТРИвожність) D (Депресія) CAM (САМотність). Аналіз виділених категорій когнітивних процесів, афектів, часу

ISSN 2308-3743 (Online), ISSN 2227-1376 (Print)

(C) Засєкіна Л., 2021. Ця стаття відкритого доступу на умовах CC BY-NC 4.0 
у творах студентів та методологічні засади КПТ дали змогу вибудувати зміст та структуру онлайн ресурсу для студентів.

Висновки. Онлайн КПТ $є$ важливим інноваційним форматом надання психологічної самодопомоги студентам в умовах соціальної ізоляції.

Ключові слова: онлайн когнітивно-поведінкова терапія, тривожність, депресія, соціальна тривожність, резілієнтність, 3D CAM.

Zasiekina Larysa. Online cognitive-behavioral therapy of students' emotional distress during the COVID-19 pandemic.

Purpose. The COVID-19 pandemic is currently being transformed into the second wave, associated with mental health. Notwithstanding the fact that students have not been considered a vulnerable group for a long time during the pandemic, recent research shows that they experience acute stress, anxiety, loneliness and depression under the circumstances of forced social isolation. The study aims to examine emotional distress in students during the pandemic COVID-19, and to develop online cognitive-behavioral therapy (CBT) for students.

Methods. The study applies Ryff Scale for Psychological Well-Being, Beck Depression Inventory, Protective Factors for Resilience Scale (PFRS), Beck Anxiety Inventory. The computer program Linguistic Inquiry and Word Count (LIWC) was used for thematic analysis.

The results of assessing psychological well-being indicate that subscales of environmental mastery, the establishment of quality ties to other, self-acceptance, and the pursuit of meaningful goals and a sense of purpose in life are represented at the lowest levels. Therefore, developing an online CBT for students was focused on these aspects of students' psychological well-being. The results of linear regression analysis indicate that anxiety, depression and resilience taken together is a significant predictor of psychological well-being. However, only depression is an independent significant predictor of students' psychological well-being. Considering anxiety and loneliness as the key themes mentioned in the students' essays, as well as social anxiety, aligned with the deficit of communicative situations during pandemic, online CBT aims to reduce depression and loneleness, anxiety and social anxiety. Therefore, the online CBT is called 3 -D SAM. The content and structure of online CBT for students are aligned with key categories of cognitive processes, affects, time, represented in the students' essays, and the methodological foundations of CBT.

Conclusions. The online CBT is an important innovative psychological selfsupport for students during COVID-19 pandemic.

Key words: online cognitive-behavioral therapy, anxiety, depression, social anxiety, resilience, 3D SAM.

Лариса Засекина. Онлайн когнитивно-поведенческая терапия эмоционального дистресса студентов в период пандемии COVID-19.

Цель. COVID-19 пандемия на современном этапе трансформируется во вторую волну пандемии, связанную с пандемией расстройств психического здоровья. Несмотря на тот факт, что студенты долгое время не считались 
уязвимой категорией населения в период пандемии, результаты последних исследований доказывают, что они переживают актуальный стресс, тревожность, одиночество и депрессию в условиях вынужденной социальной изоляции. Цель исследования состоит в эмпирическом изучении эмоционального дистресса студентов во время пандемии COVID-19 и научном обосновании авторского онлайн ресурса, основанного на когнитивноповеденческой терапии (КПТ).

Методы. В исследовании использовались методы теоретического и эмпирического анализа, в частности психодиагностический инструментарий, представленный шкалой психологического благополучия К. Рифф, шкалой депрессии А. Бека, шкалой резилиентности С. Хамса и др., шкалой тривожности А. Бека. Для тематического анализа использовалась компьютерная программа Linguistic Inquiry and Word Count (LIWC).

Результаты исследования психологического благополучия свидетельствуют о том, что самый низкий уровень имеют субшкалы положительного отношения к другим, самопринятие, цели в жизни и управление окружением. Поэтому при разработке онлайн ресурса именно эти аспекты психологического благополучия были учтены. Результаты линейного регрессионного анализа свидетельствуют о том, что тревожность, депрессия и резилиентность является совокупно значимым предиктором психологического благополучия. В то же время только депрессия является независимым значимым предиктором психологического благополучия студентов. Учитывая тревожность и одиночество как основные проблемы, которые отмечали студенты в своих сочинениях, а также социальную тревожность, растущую в условиях невозможности развивать коммуникативные умения, а терапия была направлена на работу с этими негативными эмоциональными состояниями. Соответсвенно, онлайн ресурс получил название 3 (Тревожность) D (Депрессия) САМ (Одиночество). Анализ выделенных категорий когнитивных процессов, аффектов, времени в произведениях студентов, и методологические основы КПТ определили содержание онлайн ресурса для студентов и его структуру.

Выводы. Онлайн форма КПТ является важным инновационным форматом психологической самопомощи студентам в условиях социальной изоляции.

Ключевые слова: онлайн когнитивно-поведенческая терапия, тревожность, депрессия, социальная тревожность, резилиентность, 3D CAM.

Вступ. Безпрецедентне поширення SARS-CoV-2 кардинально змінило життя людей, негативно позначаючись на їхньому фізичному й психічному здоров”ї. Серед основних драматичних наслідків пандеміi COVID-19 є зростання емоційного дистресу, зокрема рівня тривожності, депресії, актуального стресу та посттравматичного стресового розладу (ПТСР) (Passavanti et al., 2021). Результати останніх досліджень свідчать про те, що COVID-19 пандемія на 
сучасному етапі трансформується у другу хвилю пандемії, пов'язану 3 пандемією розладів психічного здоров'я (Kopelovich \& Turkington, 2021). Це зумовлює необхідність розробки інноваційних форм надання психологічної допомоги, враховуючи зростання кількості осіб, які їі потребують, та соціальні обмеження, які досі переважають у більшості країн. Серед таких інноваційних форм є дистанційна форма психологічної допомоги, яка по-різному означається в науковій літературі: віддалена, онлайн, віртуальна, дігіталізована.

Ситуація пандемії COVID-19 зумовила переживання емоційного дистресу різними верствами населення, особливе місце серед яких посідають студенти. Незважаючи на той факт, що студенти упродовж тривалого часу не вважалися вразливою категорією населення у період пандемії, результати останніх досліджень доводять, що вони переживають актуальний стрес, тривожність, самотність та депресію в умовах вимушеної соціальної ізоляції ( Засєкіна, 2021). Зокрема емоційний дистрес студентів пов'язують із переживаннями за здоров'я своїх батьків та старших родичів, віддалені умови навчання та можливість успішного складання сесії, доцільність вакцинування, втрату звичних соціальних зв'язків, погіршення матеріального становища через неможливість підробітків на тимчасовій роботі. Ситуація в Україні погіршується тим, що низька вакцинованість населення призвела до високої смертності (на 11.11.2021 за даними Університету Джонса Гопкінса Україна посідає третє місце у світі за кількістю смертей, кількість нових випадків упродовж 28-денного періоду становить 573.251, кількість смертей 15.096). Ця негативна динаміка призвела до того, що в Україні посилились соціальні обмеження та соціальна дистанція між людьми.

Як зазначає Л. Фоулкес та С. Блейкмор (2021), віковий період 1024 років є найбільш сенситивним до соціальної взаємодії, необхідної для здорового мозку та когнітивного розвитку. Саме у цей віковий період завдяки тісним соціальним зв'язком формується безпечна прив'язаність із релевантним колом однолітків, а також закріплюється почуття приналежності до ширшої групи осіб із спільними інтересами. Враховуючи той факт, що соціальна взаємодія під час пандемії є обмеженою або несхвальною через переважання правил соціальної дистанції та ізоляції, ключові завдання цього вікового періоду залишаються невирішеними. Така ситуація зрештою негативно впливає на стан психічного здоров’я юнаків. 
За результатами наших попередніх крос-національних досліджень, українські студенти подібно до студентів інших країн переживають емоційний дистрес, пов'язаний із відсутністю чітких даних про природу вірусу та можливості його лікування, невизначеністю щодо подальшого розвитку подій, здоров'я своїх близьких, труднощами у навчанні (Schiff, Zasiekina, Pat-Horenczyk, \& Benbenishty, 2021). Цікавим результатом крос-національного дослідження $\epsilon$ встановлений нижчий рівень довіри щодо вакцинації українських студентів порівняно зі студентами Ізраїлю.

Зважаючи на негативні наслідки соціальної ізоляції та іiі негативний вплив на психічне здоров'я студентів, особливої значущості набуває онлайн психологічна допомога, яка могла б знижувати емоційний дистрес і застосовуватись у дистанційному режимі. Останні дослідження з проблеми дистанційної психологічної допомоги Н. Алаві та ін. (2020) свідчать про те, що когнітивноповедінкова терапія (КПТ) як науково-обгрунтований метод надання психологічної допомоги при переважній більшості проявів емоційного дистресу $\epsilon$ найбільш ефективною для дистанційного формату. Зокрема вчені пропонують протокол надання онлайн допомоги упродовж 9 тижнів, який включає самоедукацію щодо основних проблем, пов'язаних із психічним здоров'ям внаслідок COVID-19, розвиток поведінкових вмінь та домашні завдання. Водночас ефективність цього протоколу знаходиться ще на стадії рандимізованого контрольованого дослідження. С. Капелович та Д. Туркінгтон (2021) в результаті своїх досліджень розробили онлайн форму КПТ для осіб із психотичними розладами, яка містить меншу кількість сесій ніж класична форма терапії. Дистанційна КПТ використовує техніки для зменшення депресії, тривожності, безсоння, які часто поглиблюють психотичні симптоми, а також техніки для самоконтролю, тестування реальності та планування діяльності. Водночас автори наголошують на необхідності подальшого дослідження ефективності цієї програми для осіб із психотичними розладами.

Таким чином, важливість розробки онлайн форми надання психологічної допомоги студентам в умовах вимушеної соціальної ізоляції, з одного боку, та відсутність науково-обгрунтованих даних щодо ефективності такого ролу програм, зумовили актуальність дослідження. 
Мета дослідження полягає в емпіричному вивченні проявів емоційного дистресу студентів під пандемії COVID-19, та науковому обгрунтуванні авторського онлайн ресурсу, базованому на КПТ, який отримав назву 3Д САМ.

Методи та процедура дослідження. У дослідженні використовувалися методи теоретичного та емпіричного вивчення, зокрема психодіагностичний інструментарій представлений шкалою психологічного благополуччя К. Ріфф, шкалою депресії Бека, шкалою резілієнтності (PFRS) C. Хамса та ін., шкалою тривоги А. Бека. Для тематичного аналізу творів студентів на тему «Мій досвід переживання карантинних обмежень у період пандемії» використовувалася комп'ютерна програма Linguistic Inquiry and Word Count (LIWC).

Враховуючи результати дослідження А. Оту та ін. (2020) стосовно того, що психічне здоров'я під час пандемії найкраще операціоналізується через поняття психосоціального благополуччя, а також результати дослідження М. Верстіг та Р. Каппе (2021) про те, що резілієнтність у сукупності з програмою психологічної підтримки в університеті $є$ важливим чинником зменшення депресії та академічного стресу студентів, до діагностичного інструментарію було включено методики для вивчення резілієнтності та психологічного благополуччя. Депресія та тривожність розглядається нами як основні прояви емоційного дистресу студентів.

Вибірка дослідження містить 200 осіб студентів Волинського національного університету імені Лесі Українки (ВНУ імені Лесі Українки), з них - 184 осіб жіночої статі, та 16 - особи чоловічої статі, віком від 18 до 40 років. Дослідження погоджено Етичним комітетом ВНУ імені Лесі Українки (№ 4 від 1. 04. 2020). Під час опитування студенти перебували на дистанційному навчанні, відтак, дослідження здійснювалося на основі Google форми. Студентам пропонували взяти участь у дослідженні студентські декани, які $€$ представниками студентського самоврядування на факультетах в університеті. Початково 224 студенти заповнили опитувальники, водночас 24 форми виявилися недійсними з різних причин.

Описова статистика вибірки представлена у таблиці 1. 
Табличя 1

\section{Описова статистика вибірки}

\begin{tabular}{|c|c|}
\hline \multicolumn{2}{|c|}{ Демографічні характеристики досліджуваних } \\
$(\mathrm{n}=200)$
\end{tabular}

Обговорення результатів. Результати кореляційного аналізу 3 допомогою коефіцієнта $\mathrm{r}$ Пірсона (див. табл. 2) свідчать про те, що існує позитивний, хоча й слабкий кореляційний зв'язок між змінними психологічного благополуччя та резілієнтності, та негативні кореляційні зв'язки між змінними психологічного благополуччя та депресії, резілієнтності та тривожності, резілієнтності та депресії. Такі дані узгоджуються із сучасними дослідженнями, у яких зазначається, що резілієнтність має негативні кореляційні зв'язки 3 різними проявами емоційного дистресу, передусім, тривожністю й депресією (Versteeg \& Kappe, 2021).

Таблиия 2

Результати кореляційного аналізу змінних психологічного

благополуччя, депресії, тривожності та резіліснтності (n=200)

\begin{tabular}{|l|c|c|c|c|}
\hline & $\begin{array}{l}\text { Психологічне } \\
\text { благополуччя }\end{array}$ & Депресія & Тривожність & Резілієнтність \\
\hline $\begin{array}{l}\text { Психологічне } \\
\text { благополуччя }\end{array}$ & 1,000 & $-0,380^{*}$ & 0,005 & $0,277^{*}$ \\
\hline Депресія & $-0,380^{*}$ & 1,000 & $0,280^{*}$ & $-0,533^{* *}$ \\
\hline Тривожність & 0,005 & $0,280^{*}$ & 1,000 & $-0,299^{*}$ \\
\hline Резілієнтність & $0,277^{*}$ & $-0,533^{*}$ & $-0,299^{*}$ & 1,000 \\
\hline
\end{tabular}

Примітка * $\mathrm{p} \leq 0,05 ; * * \mathrm{p} \leq 0,01$ 
Результати проведеного дослідження свідчать про те, що $46 \%$ студентів не мають ознак депресії, легка форма депресії діагностована у 18\% студентів, середній рівень визначено у 28\% респондентів, високий рівень виявлено у 8\% студентів. Таким чином, більше третини студентів потребувало психологічної допомоги у період вимушеної соціальної ізоляції під час карантину. Подібна ситуація спостерігається 3 проявами тривожності. Так, 43\% студентів не виявили ознак тривожності, $15 \%$ студентів мали легку форму тривожності, 39\% досліджуваних виявили середній рівень тривожності. Високий рівень тривожності діагностовано у $3 \%$ респондентів. Відтак, майже половина студентів потребувала психологічної допомоги для зниження рівня тривожності під час карантинних обмежень та дистанційного навчання. Для визначення предикторів психологічного благополуччя студентів було здійснено лінійний регресійний аналіз, де залежною змінною є психологічне благополуччя, а предиктори відновлюваність, тривожність та депресія (див. табл. 3).

Таблиця 3

Результати регресійного аналізу із залежною змінною «психологічне благополуччя» $(\mathbf{n}=200)$

\begin{tabular}{|c|c|c|c|c|c|}
\hline \multirow{2}{*}{ Модель } & \multicolumn{2}{|c|}{$\begin{array}{c}\text { Нестандартизовані } \\
\text { коефіціснти }\end{array}$} & $\begin{array}{c}\text { Стандартизовані } \\
\text { коефіціснти }\end{array}$ & \multirow{2}{*}{ Знач. } \\
\cline { 2 - 5 } & В & $\begin{array}{c}\text { Стд. } \\
\text { похибка }\end{array}$ & Бета & 1,915 & 0,062 \\
\hline (Константа) & 3,670 & 1,917 & & $-2,170$ & 0,035 \\
\hline Депресія & $-0,093$ & 0,043 & $-0,348$ & 0,997 & 0,324 \\
\hline Тривожність & 0,032 & 0,032 & 0,142 & 0,827 & 0,413 \\
\hline Резіліснтність & 0,012 & 0,015 & 0,134 & \\
\hline
\end{tabular}

Припущення щодо лінійного зв’язку між даними, однорідності, автокореляції залишків першого порядку (Durbin Watson d=1,830), пропорція варіації змінних (середній показник толерантності $=0,758>0,1, \quad$ i $\mathrm{VIF}=1,321$, отже $1<\mathrm{VIF}>10)$, які $\epsilon$ необхідними для здійснення регресійного аналізу, були підтверджені. 
Результати лінійного регресійного аналізу свідчать про те, що тривожність, депресія та резілієнтність сукупно $є$ значущим предиктором психологічного благополуччя $(\mathrm{B}=0,412,95$ \% CI [12,32; $77,51], \beta=0,116, t=3.139, p=0,034)$. Ці результати узгоджуються із попередніми даними про те, що існує негативний кореляційний зв'язок між депресією та психологічним благополуччям. Водночас лише депресія є незалежним значущим предиктором психологічного благополуччя студентів. Це дає змогу дійти висновків про те, акцент на зменшенні тривожності та прояві депресії, 3 одного боку, та підвищенні резілієнтності, з іншого - має постати у фокусі уваги при розробці онлайн КПТ ресурсу для психологічної допомоги студентам.

Розробка авторського онлайн КПТ студентів також грунтувалася на тематичному аналізі творів студентів на тему «Мій досвід переживання карантинних обмежень у період пандемії», а також вираженні різних субшкал психологічного благополуччя студентів.

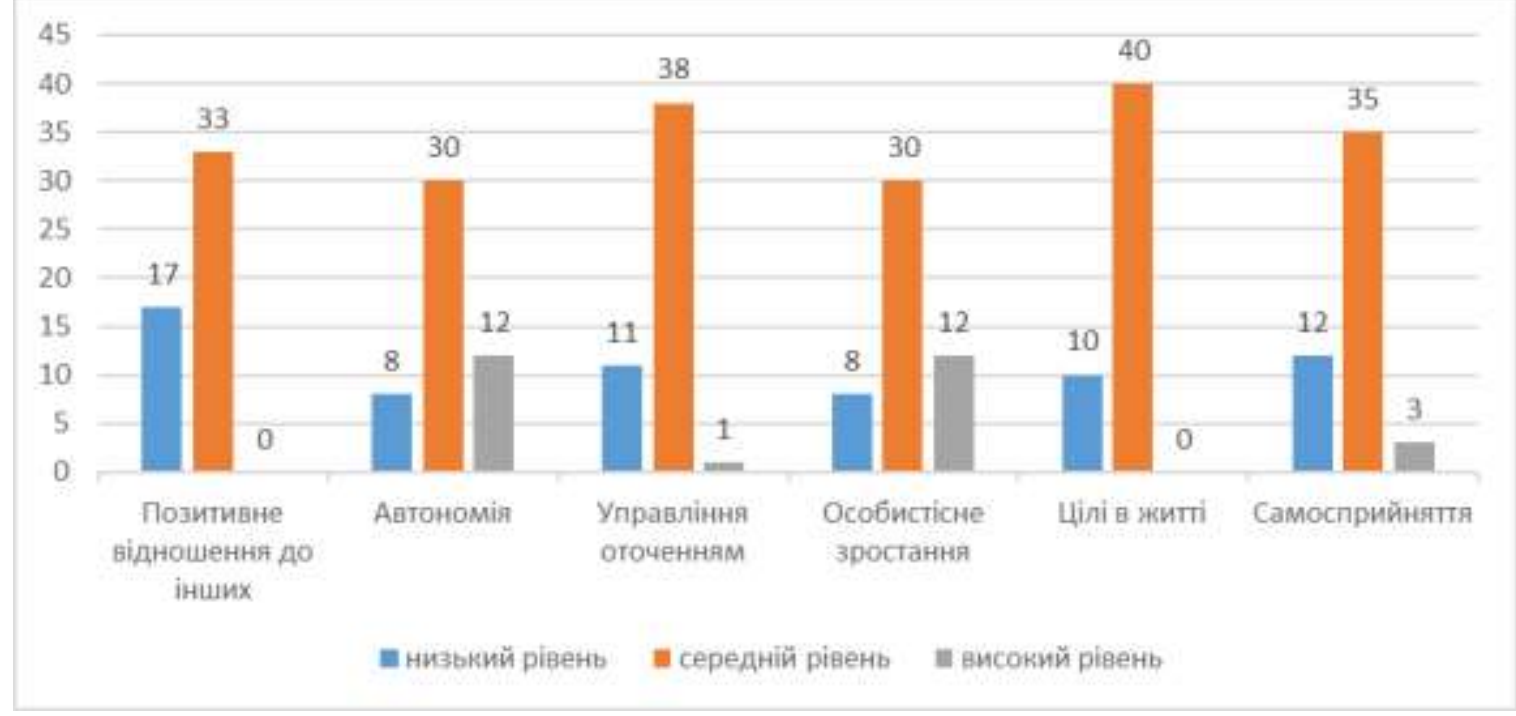

\section{Рис 1. Результати за субшкалами методики «Шкала психологічного благополуччя» К. Ріфф}

Як видно 3 рисунку 1, найнижчий рівень вираження мають субшкали позитивного ставлення до інших, самоприйняття, цілі в житті та управління оточенням. Тому при розробці онлайн ресурсу саме ці аспекти психологічного благополуччя були найбільш враховані та слугували мішенню для КПТ втручання.

Результати тематичного аналізу засвідчили основні теми, які зазначали студенти у своїх творах. Для тематичного аналізу використовувалася комп'ютерна програма Linguistic Inquiry and Word Count (LIWC) (Pennebaker, Boyd, Jordan, \& Blackburn, 2015). 
Кожен текстовий файл твору студента аналізувався за 73 семантичними категоріями, зокрема афекти, когнітивні процеси, біологічні процеси, мотиви, робота, дім, відпочинок і т.ін.

Упродовж аналізу розгорнутих відповідей було виявлено 10 найбільш значимих психологічних категорій, які зображені у таблиці 4.

Таблицуя 4

Психологічно значущі категорії в творах студентів

\begin{tabular}{|c|c|c|}
\hline № & Категорії & Вираження у \% \\
\hline 1. & Афекти & 1,47 \\
\hline 2. & Соціальні зв’язки & 1,71 \\
\hline 3. & Когнітивні процеси & $\mathbf{7 , 6 1}$ \\
\hline 4. & Причини & 1,89 \\
\hline 5. & Сприймання & 1,06 \\
\hline 6. & Фокус на минулому & 1,71 \\
\hline 7. & Фокус на теперішньому & 1,12 \\
\hline 8. & Фокус на минулому & 0,06 \\
\hline 9. & Простір & $\mathbf{7 , 5 5}$ \\
\hline 10. & Час & $\mathbf{4 , 9 5}$ \\
\hline
\end{tabular}

Найширшою категорією є категорія когнітивні проиеси (думати, розуміти, усвідомлювати тощо), які свідчать про спробу студентів раціонально пояснити проблему та спрогнозувати майбутній хід подій. Ця категорія узгоджується з іншою категорією, представленою у творах, причинами пандемії.

(1) Епідемія коронавірусу та карантин дозволи переоцінити власне життя та основні погляди, установки. Я зрозуміла, щуо не треба чекати чогось, не відкладати щзось на потім, бо наше життя не передбачуване. Ми маємо жити кожним моментом, тут $і$ зараз, бо людина не в змозі передбачити, що буде завтра. Мабуть, глобально ие й є причиною вірусу, людська байдужість, метушня, нечутливість до теперішнього моменту. Я сприймала карантин позитивно, не зациклюватися навчанням, успішність. Головне бути щасливим та адекватного ставитися до оточуючих подій. 
(2) Під час карантину настало таке переосмислення всього, якось по-новому все почало сприйматись, почала цінувати більще те життя, яке було до пандемії.

Примітно, що у текстах із переважанням когнітивних процесів та вираженою спробою усвідомити період пандемії не залишається місце для вираження негативних емоцій. Водночас ці емоції є яскраво вираженими у творах, де таке когнітивне осмислення відсутнє.

(3) Це просто жах. Спершу був страх. Потім прийняття ситуачї. Проте неможливість переключити свою діяльність вбиває. Ця незрозуміла ситуація вводить в стан повної апатії. A саме головне скрізь переслідує самотність.

(4) Карантин дуже сильно утруднив життя. Тотальний карантин змінив усіх та усе навкруги. Економіка падає, психологічне здоров'я страждає, самотність та соціальна ізолячія зростає. Часто буває, щуо відчувається, як тиша і стіни кімнати тиснуть на мене. Наше життя та суспільство не повернеться у колишній стан. Тепер все буде по-іншому. Люди вже не зможуть повернутися до звичного ритму спілкування.

(5) Я боюсь, щуо втрачу назавжди навички спілкування. Я і так дуже переживала перед різними виступами $i$ розмовами 3 незнайомими людьми, а тепер втратила свої комунікативні можливості, мабуть, назавжди. Мені вже важко спілкуватися 3 людьми, коли я їх бачу біля себе, я впадаю в ступор.

У творах із переважанням категорії афектів практично відсутні дієслова, що означають когнітивні процеси студентів в осмисленні нового досвіду, пов'язаного із COVID-19. Таким чином, можна припустити, що психоедукаційні заняття із поясненням природи вірусу, його впливу на психічне здоров'я та опанування техніками зменшення емоційного дистресу й розвитку резілієнтності як способу подолання ситуації невизначеності може значно покращити психологічне благополуччя студентів у період пандемії в умовах вимушеної ізоляції.

Висновки і перспективи. Результати емпіричного дослідження слугували важливою базою для розробки авторської онлайн КПТ студентів, спрямованої на подолання емоційного дистресу. Враховуючи тривожність та самотність як основні проблеми, про які зазначали студенти, соціальну тривожність, яка зростає в умовах відсутності вдосконалення власних комунікативних вмінь, ресурс був 
спрямований на ці зменшення негативних проявів емоційні стани. Відповідно до цього, онлайн ресурс отримав назву 3 (ТРИвожність) D (Депресія) СAM (САМотність). 3D CAM розміщений на платформі Moodle i $\epsilon$ доступним студентам університету. Методологічною основою онлайн допомоги студентам слугувала КПТ, оскільки вона має науково-доказову базу у лікуванні тривожних і депресивних розладів. КПТ загалом і когнітивна терапія у класичній версії, запропонованій А. Беком, слугує науково-доведеним методом психотерапевтичного втручання при низці фізичних захворювань і психічних розладів (Knapp \& Beck, 2008).

До основних методологічних положень КПТ, які були використані, належать принципи емпіричності (використання когнітивних i поведінкових технік, ефективність яких $\epsilon$ науковообгрунтованою), інтерактивності (взаємозв'язок думок, емоцій, тіла та поведінки), когнітивності (робота 3 автоматичними думками, дисфункційними припущеннями та глибинними переконаннями), активності (самодопомога як спосіб покращення свого психологічного благополуччя). Онлайн КПТ складається 3 трьох блоків: робота 3 тривожністю (8 тижнів), соціальною тривожністю (8 тижнів), депресією та самотністю (8 тижнів). Студенти можуть пройти усі блоки, або обрати той, який є важливим для них. Кожне заняття триває 45-50 хвилин і включає психоедукацію, демонстрацію й опрацювання когнітивної чи поведінкової техніки та одну вправу 3 8-тижневої майндфулнес терапії, запропонованої М. Вільямсом та Д. Пенменом (Williams \& Penman, 2011). На даному етапі онлайн КПТ знаходиться на стадії рандимізованого контрольованого дослідження його ефективності.

Подяка. Онлайн КПТ студентів була розроблена в рамках партнерського проєкту «Зміцнення психічного здоров’я студентів та учнів в умовах вимушеної соціальної ізоляції під час пандемії» (20202021), грантодавцем якого є Британська рада. Збір емпіричних даних було здійснено з допомогою Мар'яни Лис, магістра психології, освітньо-професійної програми «Практична психологія (психологічне консультування та психотерапія)». Онлайн КПТ розроблена в рамках партнерського проєкту «Зміцнення психічного здоров’я студентів та учнів в умовах вимушеної соціальної ізоляції під час пандемії», в якому взяли участь ВНУ імені Лесі Українки (Лариса Засєкіна, Тетяна Гордовська), Запорізький національний університет (Наталія 
Мосол), Кам'янець-Подільський національний університет імені Івана Огієнка (Наталія Гончарук), Державний університет «Житомирська політехніка» (Наталія Харитонова, Ірина Леган).

\section{Література}

1. Засєкіна, Л. (2021). Академічна доброчесність, якість освіти та якість життя студентів в умовах дистанційного навчання під час covid-19. Наукові записки Національного університету «Острозька академія». Серія “Психологія"», (12), 41-45.

2. Alavi, N., Yang, M., Stephenson, C., Nikjoo, N., Malakouti, N., Layzell, G., ... \& Soares, C. N. (2020). Using the online psychotherapy tool to address mental health problems in the context of the COVID-19 pandemic: protocol for an electronically delivered cognitive behavioral therapy program. JMIR Research Protocols, 9(12), e24913.

3. Foulkes, L., \& Blakemore, S. J. (2021). Individual differences in adolescent mental health during COVID-19: The importance of peer relationship quality. Neuron, 109(20), 3203-3205.

4. Knapp, P., \& Beck, A. T. (2008). Cognitive therapy: foundations, conceptual models, applications and research. Brazilian Journal of Psychiatry, 30, s54-s64.

5. Kopelovich, S. L., \& Turkington, D. (2021). Remote CBT for psychosis during the COVID-19 pandemic: challenges and opportunities. Community Mental Health Journal, 57(1), 30-34.

6. Otu, A., Charles, C. H., \& Yaya, S. (2020). Mental health and psychosocial well-being during the COVID-19 pandemic: The invisible elephant in the room. International Journal of Mental Health Systems, 14, 1-5.

7. Passavanti, M., Argentieri, A., Barbieri, D. M., Lou, B., Wijayaratna, K., Mirhosseini, A. S. F., ... \& Ho, C. H. (2021). The psychological impact of COVID-19 and restrictive measures in the world. Journal of Affective Disorders, 283, 36-51.

8. Pennebaker, J. W., Boyd, R. L., Jordan, K., \& Blackburn, K. (2015). The development and psychometric properties of LIWC2015.

9. Schiff, M., Zasiekina, L., Pat-Horenczyk, R., \& Benbenishty, R. (2021). COVID-related functional difficulties and concerns among university students during COVID-19 pandemic: A binational perspective. Journal of Community Health, 46(4), 667-675.

10. Versteeg, M., \& Kappe, R. (2021). Resilience and Higher Education Support as Protective Factors for Student Academic Stress and Depression During Covid-19 in the Netherlands. Frontiers in Public Health, 1555.

11. Williams, M., \& Penman, D. (2011). Mindfulness: a practical guide to finding peace in a frantic world. Hachette UK.

\section{References}

1. Zasiekina, L. (2021). Akademichma dobrochesnist, yakist osvity, yakist zhytya studentiv $\mathrm{v}$ umovah dystantsyinogo navchannya [Academic integrity, quality 
of education, and quality of life of students under the circumstances of distant learning]. Naukovi zapysky natsionalnogo universitety Ostrozska academia- Research Notes of National University of Ostroh academy. Psychology, (12), 41-45 [in Ukrainian].

2. Alavi, N., Yang, M., Stephenson, C., Nikjoo, N., Malakouti, N., Layzell, G., ... \& Soares, C. N. (2020). Using the online psychotherapy tool to address mental health problems in the context of the COVID-19 pandemic: protocol for an electronically delivered cognitive behavioral therapy program. JMIR Research Protocols, 9(12), e24913.

3. Foulkes, L., \& Blakemore, S. J. (2021). Individual differences in adolescent mental health during COVID-19: The importance of peer relationship quality. Neuron, 109(20), 3203-3205.

4. Knapp, P., \& Beck, A. T. (2008). Cognitive therapy: foundations, conceptual models, applications and research. Brazilian Journal of Psychiatry, 30, s54-s64.

5. Kopelovich, S. L., \& Turkington, D. (2021). Remote CBT for psychosis during the COVID-19 pandemic: challenges and opportunities. Community Mental Health Journal, 57(1), 30-34.

6. Otu, A., Charles, C. H., \& Yaya, S. (2020). Mental health and psychosocial well-being during the COVID-19 pandemic: The invisible elephant in the room. International Journal of Mental Health Systems, 14, 1-5.

7. Passavanti, M., Argentieri, A., Barbieri, D. M., Lou, B., Wijayaratna, K., Mirhosseini, A. S. F., ... \& Ho, C. H. (2021). The psychological impact of COVID-19 and restrictive measures in the world. Journal of Affective Disorders, 283, 36-51.

8. Pennebaker, J. W., Boyd, R. L., Jordan, K., \& Blackburn, K. (2015). The development and psychometric properties of LIWC2015.

9. Schiff, M., Zasiekina, L., Pat-Horenczyk, R., \& Benbenishty, R. (2021). COVID-related functional difficulties and concerns among university students during COVID-19 pandemic: A binational perspective. Journal of Community Health, 46(4), 667-675.

10. Versteeg, M., \& Kappe, R. (2021). Resilience and Higher Education Support as Protective Factors for Student Academic Stress and Depression During Covid-19 in the Netherlands. Frontiers in Public Health, 1555.

11. Williams, M., \& Penman, D. (2011). Mindfulness: a practical guide to finding peace in a frantic world. Hachette UK.

Received: 28.10 .2021 Accepted: 14.11.2021 